\title{
Optimized outcome of pregnancy in a woman with Glanzmann thrombasthenia with multidisciplinary approach
}

\author{
Sujithradevi Radhakrishnan*, Gowri Dorairajan, Murali Subbaiah, Jyotsna Sharma
}

Department of Obstetrics and Gynecology, JIPMER, Pondicherry, India

Received: 13 June 2021

Accepted: 07 July 2021

\section{*Correspondence: \\ Dr. Sujithradevi Radhakrishnan, \\ E-mail: sujiradjan@gmail.com}

Copyright: () the author(s), publisher and licensee Medip Academy. This is an open-access article distributed under the terms of the Creative Commons Attribution Non-Commercial License, which permits unrestricted non-commercial use, distribution, and reproduction in any medium, provided the original work is properly cited.

\begin{abstract}
Glanzmann thrombasthenia (GT), an autosomal recessive disorder of defective platelet aggregation due to abnormalities of platelet receptor GPIIb/IIIa, can result in complication of bleeding during pregnancy. We report multidisciplinary management of a case with optimized outcome. 23 years old short statured $(142 \mathrm{~cm})$ primigravida was referred for contracted pelvis at term in labour. She was diagnosed with GT at 12 years of age during evaluation of gum bleeding, easy bruising, and prolonged post traumatic bleeding. She was born of a second-degree consanguineous marriage. At admission she was hemodynamically stable but moderately pale. Her hemoglobin was $8.7 \mathrm{~g} \%$, with 4.6 lacs platelets and clotting time of 15 minutes. Multidisciplinary team of hematologist, transfusionist and anesthetist was activated. Arranging single donor platelets in a short notice was challenging. Emergency cesarean section under general anesthesia was performed after transfusing two units packed red blood cell and 2 single donor platelets to deliver an alive male baby of $3.3 \mathrm{~kg}$. Hemostasis was secured with cautery and ligatures. Tranexamic acid infusion and sublingual misoprostol was given prophylactically. she was transfused another 4 random donor platelets during operation and postoperatively. The case details will be presented. GT have normal to high platelet counts though they are normal morphologically, they are dysfunctional. This fact needs to be recognized and referred early to equipped centres. We used component transfusion, active management of third stage and tranexamic acid for optimizing outcome due to haemorrhage. At present, there is lack of consensus regarding optimum treatment of post-partum hemorrhage in patients with GT.
\end{abstract}

Keywords: Platelet disorder, Glanzmann thrombasthenia, Pregnancy

\section{INTRODUCTION}

Glanzmann's thrombasthenia (GT) is a rare autosomal recessive disorder of platelet function characterized by deficiency or dysfunction of glycoprotein(gp) IIb-IIIa complex in the platelet membrane. ${ }^{1}$ Platelet let aggregation is impaired by the absence of the glycoprotein complex leading to formation of defective haemostatic plug and bleeding manifestations. It is a rare disease with an estimate of less than 1 in 1,000,000 population, males and females are equally affected. ${ }^{2}$ Pregnancy in women with GT is associated with increased risk of miscarriage, antepartum hemorrhage, post-partum hemorrhage and neonatal thrombocytopenia. The first line of treatment for significant bleeding and during surgical intervention in GT is administration of recombinant factor-7 (rFVIIa). We present a case of GT who underwent emergency Lower segment caesarean section (LSCS) and was managed successfully with multidisciplinary team and with single donar platelets, random donar platelet and packed red blood cells (PRBC) transfusion.

\section{CASE REPORT}

A 23 years old primi gravida with GT was admitted at 39 weeks for safe confinement in our tertiary care centre. She was diagnosed at 12 years of age with Glanzmann's thrombasthenia on evaluation for recurrent gum bleeding, easy skin bruisability and prolonged post traumatic bleeding. Gum bleeding was both spontaneous and 
following brushing which used to stop in few minutes to few hours. Post traumatic bleeding was controlled with local pressure usually, but she required fresh frozen plasma (FFP) transfusion to stop gum bleeding at which time she underwent evaluation.

She was born of a second-degree consanguineous marriage with no family history of bleeding disorders. Her initial investigation were $\mathrm{Hb}-8.5 \mathrm{~g} / \mathrm{dl}$, total count and differential count were normal, platelet count- 385000/cumm with normal morphology, coagulation profile was normal (PT, Aptt INR). Clot retraction time was good, coagulation factor FVII: $179.9 \%$, FIX: $65.5 \%$, FXI: $107.4 \%$, VWF:RCO: 72\%, fibrinogen: $282 \mathrm{mg} \%$, BT >15 min. Platelet aggregometry showed no aggregation with adenosine-di-phosphate, epinephrine and thromboxane analogue. Delayed response was seen with collagen, sluggish reaction with arachidonic acid, a primary wave with TRAP and normal aggregation with ristocetin. Lumi aggregometry using thrombin as agonist showed borderline ATP release. Kaolin clotting time using her platelet rich plasma was prolonged but normalized with freeze thawed platelet rich plasma. Thus, arrived to a diagnosis of GT.

She attained menarche at 13 years, her cycles were regular with 7-10 days, bleeding was controlled by tranexamic acid mostly.1-2 cycles in a year required packed cell and platelet transfusion. She had conceived spontaneously following non-consanguineous marriage. She was booked and followed up at local hospital. Her antenatal period was un-eventfull except for anemia for which she received 2 packed cells, one in second trimester and one in third trimester. She had gum bleeding throughout her antenatal period managed conservatively. There was no vaginal bleeding or any other bleeding manifestation in the ante natal period.

She was referred to our center only at 39 weeks in early labour. she was short statured $142 \mathrm{~cm}$ height with contracted pelvis and needed emergency caesarean section. Multidisciplinary team of hematologist, anesthetist and transfusion medicine were activated.

Since factor rFVIIa could not be arranged in short notice, single donor platelets (SDP) were transfused just prior to shifting to operation theatre, lower segment caesarean section was done under general anesthesia with subumbilical midline vertical skin incision in order to minimize bleeding, to deliver a $3.3 \mathrm{~kg}$ male baby with good Apgar score. Intra operatively mild uterine atonicity was present managed by oxytocin and methyl ergometrine and tranexamic acid. Intraperitoneal drain was placed prophylactically and abdomen closed in layers after achieving perfect haemostasis. Intra operative blood loss was $800 \mathrm{ml}$. She was transfused four RDP and one packed cells transfusion during the operation. She received tranexemic acid $1 \mathrm{~g} \mathrm{IV} 8^{\text {th }}$ hourly during first 24 hours of section. One more PRBC and 4 RDP were transfused in the immediate post-operative period. Post-operative period was uneventful, drain was removed on second day. The wound healed well. There was no secondary PPH during hospital stay. At discharge her Hb-10.7 g\%, platelet- 3.5 lakhs. Baby was fine and was planned for evaluation of platelet function disorder at 3 months of age by paediatrician.

\section{DISCUSSION}

GT is an autosomal recessive disorder of platelet aggregation caused by quantitative or qualitative defects in integrins $\alpha \mathrm{IIb}$ and $\beta 3$. These integrins are encoded by the ITGA2B and ITGB3 genes and form platelet glycoprotein (GP)IIb/IIIa, which acts as the principal platelet receptor for fibrinogen ${ }^{3}$. The ITGA2B and ITGB3 genes are located on chromosomes $17 \mathrm{q} 21.31$ and $17 \mathrm{q} 21.32$, respectively. ${ }^{4}$ It was first described by Swiss paediatrician Eduard Glanzmann in $1918 .{ }^{5}$ Incidence of GT is more in selected population such as the French Romani, South Indian Hindus, Iraqi Jews, and Jordanian nomadic tribes where consanguinity is common. ${ }^{6,7}$

Males and females are equally affected. The gene encoding for GPIIb-IIIa is carried on chromosome $17 \mathrm{GT}$ is classified into three types based on the proportion of normal glycoproteins, they are type-1 individuals with $<5 \%$ of normal GP-IIb-IIIa levels, type-II will have 10 $20 \%$ normal GP-IIb-IIIa and type-III will have normal levels of GP-IIb-IIIa levels with functional inactivity. ${ }^{8}$ Type $\mathrm{I}$ is the most common subtype and accounts for around $78 \%$ of patients with GT type II and type III (functional variant in receptor) constituting around $14 \%$ and $8 \%$ of cases, respectively; there are currently 38 known mutations in glycoprotein $\mathrm{IIb}$ and 25 in glycoprotein IIIa. ${ }^{8,9}$ Most common manifestations are mucocutaneous bleeding like epistasis and gum bleeding, heavy menstrual bleeding and prolonged post traumatic bleeding. Less common manifestations are gastrointestinal bleeding, hematuria while intracranial haemorrhage and hemarthrosis are rare. Usually diagnosed during childhood as in our case.

Pregnancy in GT is associated with increased risk of intrapartum and postpartum bleeding hence should be managed in a tertiary centre with a multidisciplinary team. Though most complications of bleeding occur at the time of delivery, management of the pregnant GT patients should start in the prenatal period with counselling about pregnancy-associated risks and screening of the father in consanguineous marriage to identify at-risk fetus. 15-30\% of patients are refractory to transfusion and a significant number of women develop antibodies to HLA or GPIIb/IIIa following platelet transfusion. ${ }^{9,10}$ Hence, platelet transfusions should be reserved only for major surgeries, life-threatening bleeding, and significant bleeding that does not respond to conservative measures. Transfusions in women of reproductive age should ideally be avoided as the antibodies can cross the placenta and affect the fetus. ${ }^{11}$ Management of bleeding during delivery is by antifibrinolytics, platelet transfusion and with 
recombinant factor VIIa (rFVIIa). Regional anaesthesia is contraindicated. Recombinant activated factor VII (rFVIIa) is approved by the European Medicines Agency (EMA) and the FDA for the treatment of patients with GT. ${ }^{12}$

Recommended dose for acute bleeding is perioperative dosing of $90 \mathrm{mcg} / \mathrm{kg}$ immediately before surgery and every two hours during the procedure, followed by every 2-6 hours postoperatively to prevent post-surgical bleeding. Though it is the first line of management in case of surgical intervention, due to its cost effect and non-availability it is not used frequently. In our case due to late referral there was not enough time and resource to arrange rFVIIa. So, we transfused SDP just before the section and IV antifibrinolytics for first 24 hours. Desmopressin is also used to control bleeding in some studies. Allogeneic stem cell transplantation has been successfully performed in selected patients with severe recurrent bleeding using reduced intensity conditioning with good clinical outcomes. $^{13,14}$ Gene therapy is highly promising in providing a cure for patients with GT, with significant progress made using different techniques, vectors and model organisms. ${ }^{15-17}$ However, further advances that allow safe transgene delivery and stable expression in human models are still required. ${ }^{10}$

\section{CONCLUSION}

Pregnancy in GT should be managed in a tertiary care hospital with multidisciplinary team centre. The cases should be referred and admitted well before delivery for best outcomes. Bleeding can be controlled with SDP, RDP, PRBC and tranexamic acid infusion in developing countries where rFVIIa is not easily accessible or affordable.

Funding: No funding sources

Conflict of interest: None declared

Ethical approval: Not required

\section{REFERENCES}

1. Sherer DM, Lerner R. Glanzmann's thrombasthenia in pregnancy: a case and review of the literature. Am J Perinatol. 1999;16(6):297-301.

2. Botero JP, Lee K, Branchford BR, Bray PF, Freson K, Lambert MP, et al. Glanzmann thrombasthenia: genetic basis and clinical correlates. Haematologica. 2020;105(4):888-94.

3. Plow EF, Pesho MM, Ma Y-Q. Integrin alpha IIb beta 3. In: Michelson AD, eds. Platelets. Amsterdam, Boston: Academic Press; 2007: 165-178.

4. French DL. The molecular genetics of Glanzmann's thrombasthenia. Platelets. 1998;9(1):5-20.
5. Glanzmann E. Hereditary hemorrhagic thrombasthenia: A contribution on the pathology of blood platelets. In: Marshall A, Lichtman JL, Spivak, Boxer LA, Shattil SS, Edward S, eds. Hematology. Amsterdam, Boston: Academic Press; 2000: 113-14.

6. Nurden AT, Fiore M, Nurden P, Pillois X. Glanzmann thrombasthenia: a review of ITGA2B and ITGB3 defects with emphasis on variants, phenotypic variability, and mouse models. Blood. 2011;118(23):5996-6005.

7. Toogeh G, Sharifian R, Lak M, Safaee R, Artoni A, Peyvandi F. Presentation and pattern of symptoms in 382 patients with Glanzmann thrombasthenia in Iran. Am J Hematol. 2004;77(2):198-9.

8. Magudapathi C, Kannan S. Glanzmann's Thrombasthenia Complicating Pregnancy. J Obstet Gynaecol India. 2014;64(1):3-5.

9. George JN, Caen JP, Nurden AT. Glanzmann's thrombasthenia: the spectrum of clinical disease. Blood. 1990;75(7):1383-95.

10. Poon MC, Di Minno G, d'Oiron R, Zotz R. New Insights Into the Treatment of Glanzmann Thrombasthenia. Transfus Med Rev. 2016;30(2):929.

11. Siddiq S, Clark A, Mumford A. A systematic review of the management and outcomes of pregnancy in Glanzmann thrombasthenia. Haemophilia. 2011;17(5):858-69.

12. Inc NN. NovoSeven RT [package insert], 2019. Available at: https://www.novo-pi.com/novosevenrt. Accessed on 1 June 2021.

13. Bellucci S, Damaj G, Boval B, Rocha V, Devergie A, Yacoub AI, et al. Bone marrow transplantation in severe Glanzmann's thrombasthenia with antiplatelet alloimmunization. Bone Marrow Transplant. 2000;25(3):327-30.

14. Ramzi M, Dehghani M, Haghighat S, Nejad HH. Stem Cell Transplant in Severe Glanzmann Thrombasthenia in an Adult Patient. Exp Clin Transplant. 2016;14(6):688-90.

15. Wilcox DA, Olsen JC, Ishizawa L, Bray PF, French DL, Steeber DA, et al. Megakaryocyte-targeted synthesis of the integrin beta (3)-subunit results in the phenotypic correction of Glanzmann thrombasthenia. Blood. 2000;95(12):3645-51.

16. Fang J, Hodivala DK, Johnson BD, Du LM, Hynes RO, White GC, et al. Therapeutic expression of the platelet-specific integrin, alphaIlbbeta3, in a murine model for Glanzmann thrombasthenia. Blood. 2005;106(8):2671-9.

17. Sullivan SK, Mills JA, Koukouritaki SB, Vo KK, Lyde RB, Paluru P, et al. High-level transgene expression in induced pluripotent stem cell-derived megakaryocytes: correction of Glanzmann thrombasthenia. Blood. 2014;123(5):753-7.

Cite this article as: Radhakrishnan S, Dorairajan G, Subbaiah M, Sharma J. Optimized outcome of pregnancy in a woman with Glanzmann thrombasthenia with multidisciplinary approach. Int J Reprod Contracept Obstet Gynecol 2021;10:3242-4. 